\title{
RELAÇÕES ENTRE TECNOLOGIAS DIGITAIS E LIVRO DIDÁTICO NO ENSINO DE ESPANHOL: PROMOVENDO O LETRAMENTO DIGITAL
}

\author{
RELATIONSHIPS BETWEEN DIGITAL TECHNOLOGIES AND \\ COURSEBOOK IN SPANISH TEACHING: PROMOTING DIGITAL \\ LITERACY
}

\author{
Luanna Melo Alves* \\ Samuel de Carvalho Lima**
}

\begin{abstract}
Resumo: Considerando o contexto de ensino de Espanhol como Língua Estrangeira (ELE) nas escolas públicas, realizamos uma investigação exploratória para flagrar as relações entre as tecnologias digitais e o livro didático utilizado no Ensino Médio. Elucidamos as tecnologias digitais pressupostas ou ancoradas nas atividades propostas em um livro didático do guia de livros didáticos do Ensino Médio do Programa Nacional do Livro Didático (PNLD) do ano de 2018. Além disso, salientamos as potencialidades para a promoção do letramento digital dos alunos. A análise dos dados revelou que $13,4 \%$ das atividades são ancoradas no computador ou no celular conectado à internet e promovem, em tese, 8 tipos de letramento digital, a saber: letramento em pesquisa, letramento em informação, letramento em filtragem, letramento intercultural, letramento em hipertexto, letramento impresso online, letramento em rede, letramento pessoal.
\end{abstract}

Palavras-chave: Tecnologias digitais. Livro didático. Ensino de espanhol. Letramento digital.

Abstract: Considering the context of the teaching of Spanish as a Foreign Language (SFL) at public schools, we did an exploratory research to highlight the relationships between digital technologies and the textbook used at High School. We elucidate the presupposed or anchored digital technologies in activities found in the textbook of the guide of textbooks for High School of the National Program of the Textbooks (PNLD) of the year 2018. Besides, we highlighted the potentialities to promote students' digital literacy. Dada analysis revealed that $13.4 \%$ of activities are anchored in computer or smartphone with internet connection and promote, in theory, 8 types of digital literacy, namely: research literacy, information literacy, filtering literacy, intercultural literacy, hypertext literacy, online-print literacy, network literacy, personal literacy.

Keywords: Digital technologies. Textbook. Spanish teaching. Digital literacy.

\section{Introdução}

Face à ampliação das práticas sociais mediadas pelas tecnologias digitais, destacamos, neste trabalho investigativo, a promoção do letramento digital como condição necessária para que a escola contemporânea atue de forma eficaz na formação integral do aluno, inserindo-o como sujeito atuante na comunidade de que participa. Assim, o processo de ensino-aprendizagem pressupõe considerar as condições

\footnotetext{
* Mestranda do Programa de Pós-Graduação em Ensino (POSENSINO - UERN/IFRN/UFERSA). Professora de Língua Espanhola do IFRN campus Lajes. E-mail: luanna.alves@ifrn.edu.br

** Pós-doutor em Ciências da Educação pela Universidade do Minho. Professor do Programa de PósGraduação em Ensino (POSENSINO), IFRN campus Mossoró. E-mail: samuel.lima@ifrn.edu.br
} 
favoráveis para o desenvolvimento de competências necessárias para a comunicação através de tecnologias digitais.

A utilização das tecnologias digitais vem sendo amplamente discutida nas reflexões teóricas e metodológicas para a formulação de propostas de ensino no contexto de línguas (ROJO, 2012; 2013a; 2013b). Assim, impulsionamo-nos a investigar a adoção de estratégias que contemplem de forma eficaz o uso das tecnologias digitais nas aulas de Espanhol como Língua Estrangeira (doravante ELE) e questionamo-nos: qual o papel do livro didático na expansão de práticas comunicativas mediadas pelas tecnologias digitais?

Nosso objetivo neste artigo é flagrar as relações entre as tecnologias digitais e o livro didático utilizado nas aulas de ELE do Ensino Médio da escola pública brasileira. Para isso, elucidamos as tecnologias digitais pressupostas ou ancoradas nas propostas de atividades presentes em livro didático do guia de livros didáticos do Ensino Médio do Programa Nacional do Livro Didático (PNLD) do ano de 2018, salientando as potencialidades para a promoção do letramento digital dos alunos.

No que se refere à organização do nosso texto, para além desta introdução, na seção das escolhas teórico-metodológicas, resenhamos os autores que nos possibilitam elaborar uma lupa investigativa com a qual possamos fazer uma análise exaustiva do livro didático de ELE, além de apresentar as justificativas das escolhas e da organização dos dados da pesquisa. Posteriormente, nossos resultados são apresentados através de tabelas que quantificam a frequência de tecnologias digitais e tipos de letramentos, que são discutidos qualitativamente. Por fim, na seção de considerações finais, apresentamos implicações pedagógicas da investigação e sugerimos continuidade de pesquisa.

\section{Escolhas teórico-metodológicas}

O ensino de espanhol no Brasil é marcado por progressos e rupturas, sendo que, recentemente, temos estado em condição de alerta e de luta diante o retrocesso de medidas que excluem a língua espanhola do itinerário formativo da Educação Básica. $\mathrm{O}$ Instituto Federal de Educação, Ciência e Tecnologia do Rio Grande do Norte (IFRN) utilizou-se de certa autonomia para garantir a continuidade da oferta de ensino de ELE. Nesse contexto, a disciplina de Espanhol possui carga-horária de 90 horas, que são distribuídas ao longo de 1 ano letivo. Todos os alunos recebem material didático, isto é, livro didático da coleção aprovada pelo PNLD 2018.

Segundo Oliveira (2014), o livro didático atua como orientador e, em muitos casos, norteador de conteúdos e procedimentos didáticos por parte do professor em aulas de língua estrangeira. No contexto de tantas diversidades que constituem a oferta do ensino de línguas na escola pública brasileira, não é de se surpreender quando o livro didático se configura como o único recurso para alunos e professores.

Percebemos que os livros didáticos da atualidade dialogam mais com o aprendiz, a partir de propostas dinâmicas, baseadas em questionamentos desde a introdução de cada capítulo, mesmo antes de apresentar conteúdo sistematizado, já lançam as perguntas ao aprendiz. Apresentam muito mais atividades, não expondo os conteúdos de maneira estruturada em blocos temáticos, mas por meio de indagações os conteúdos vão aparecendo. Os questionamentos ao aluno são apresentados desde a 
primeira página da unidade, de forma mais direta com perguntas simples sobre aspectos globais da língua, como também, exercícios mais estruturados e mais complexos.

$\mathrm{O}$ aspecto que destacamos nesta pesquisa está relacionado à questão da dinamicidade das práticas sociais, analisando em que medida o material didático vem se articulando às práticas de letramento digital. Aliar os estudos de espanhol às práticas contemporâneas que pressupõem usos diversos de tecnologias digitais pode promover propostas de atividades que compreendem as tecnologias como recursos indissociáveis para o uso efetivo da língua estrangeira.

Para se utilizar de maneira eficiente as ferramentas digitais, atualmente, tão presentes na dinâmica cotidiana, é imprescindível o domínio dos letramentos digitais, que para Dudeney, Hockly e Pegrum (2016, p. 17) são "habilidades individuais e sociais necessárias para interpretar, administrar, compartilhar e criar sentido eficazmente no âmbito crescente dos canais de comunicação digital". Os autores reiteram que todos os segmentos da sociedade apelam para a promoção de competências próprias do século XXI, tais como: "criatividade e inovação, pensamento crítico e capacidade de resolução de problemas, colaboração e trabalho em equipe, autonomia e flexibilidade, aprendizagem permanente" e afirmam que no centro dessas habilidades está o manuseio das tecnologias digitais.

Zacharias (2016, p. 21) assinala que o letramento digital parte de um pluralismo de competências, "[...] exige tanto a apropriação das tecnologias, como usar o mouse, o teclado, a barra de rolagem, ligar e desligar os dispositivos, quanto o desenvolvimento de habilidades para produzir associações e compreensões nos espaços multimidiáticos".

Com a incorporação dos suportes textuais digitais, reflexões sobre as práticas de leitura e escrita se fizeram necessárias, a partir das quais, surgiram possibilidades de uso e manuseio das tecnologias digitais. Repensou-se, assim, as concepções de leitor passivo e de leitor ativo, sendo dever da escola a construção da ponte pela qual o sujeito transforme a sua condição de leitor aprendiz para leitor especialista (LEÓN, 2016).

As práticas contemporâneas de ler e escrever apontam novos desafios aos letramentos que abrangem a multiplicidade de linguagens, semioses e mídias envolvidas na construção de sentido para os textos multimodais da atualidade, como também, envolvem a pluralidade e a diversidade cultural trazidas pelos autores/leitores contemporâneos (ROJO, 2012).

Para a elucidação das relações entre as tecnologias digitais e o livro didático no ensino de espanhol, dialogamos, mais especificamente, com as contribuições acerca do letramento digital, de modo a construir uma lupa com a qual possamos realizar uma análise exaustiva do nosso objeto de estudo. Hague e Payton (2010) apresentam um conjunto de competências que compõem o letramento digital. São eles: habilidades funcionais; criatividade; pensamento crítico e avaliação; entendimento social e cultural; colaboração; habilidade de encontrar e selecionar informações; comunicação efetiva; segurança eletrônica. Para as autoras, a concepção do letramento digital não deve partir, apenas, da compreensão ou uso das tecnologias. Segundo as autoras, o entendimento de questões sociais e culturais, o pensamento crítico e a criatividade fazem parte de um conjunto de práticas que os alunos precisam envolver em torno do manuseio dos recursos ou necessidade para sua inserção efetiva em qualquer tipo de cultura, sendo, deste modo, fatores indispensáveis para a promoção do letramento digital. 
Com o uso das tecnologias digitais sendo pensado também na perspectiva dos letramentos, podemos explorar o trabalho com textos, de modo que leve o aluno a compreender e refletir sobre as propostas e temas apresentados, favorecendo a interação entre os indivíduos e objetos envolvidos. Com isso, depreendemos que o professor de ELE, tendo consciência das potencialidades interativa da web e de outros recursos tecnológicos, pode explorar e/ou adaptar, mais facilmente, propostas didáticopedagógicas com esse tipo de abordagem apresentada no livro didático para o ensino de ELE. Desse modo, pode promover o letramento digital em uma perspectiva de formação de um sujeito autônomo, capaz de compreender e gerenciar informações em qualquer portal digital nas mais diversas situações, transpondo esse conhecimento aos espaços escolares e não escolares, refletindo sobre as informações, interagindo com seus pares e buscando, constantemente, fontes de conhecimento nos ambientes virtuais.

Em face do objetivo, nossa investigação se configura como uma pesquisa exploratória para qual adotamos os seguintes procedimentos metodológicos: 1) acesso ao material didático; 2) identificação das propostas de atividades que estabelecem relação com tecnologias digitais; 3) caracterização dos letramentos digitais que são pressupostos nessas atividades.

Nosso corpus foi coletado do primeiro livro da coleção Cercanía Joven (COIMBRA; CHAVES, 2016), por ser o livro didático adotado em nossa instituição de ensino. A obra está dividida em 3 unidades didáticas, e cada unidade composta por 2 capítulos, perfazendo um total de 6 capítulos; ao final de cada unidade são apresentados tópicos extras com temáticas culturais, indicações de leituras e sites e um projeto de trabalho interdisciplinar envolvendo a literatura e outras áreas do conhecimento. Nosso corpus está constituído, portanto, de atividades voltadas para o desenvolvimento das habilidades comunicativas em língua espanhola (ler, falar, ouvir e escrever), atividades estas, que se utilizam de algum recurso tecnológico ou mídia digital para a sua mediação.

$\mathrm{Na}$ reflexão sobre as relações entre as tecnologias digitais e as atividades presentes no livro didático, cabe ponderar sobre o índice de interatividade subjacente às atividades que se ancoram nas tecnologias. O recurso tecnológico é utilizado apenas de forma mecânica e reprodutor de ações, sem promover a interação entre os sujeitos e objetos envolvidos, ou a relação entre recurso tecnológico e livro didático, de fato, promove o letramento digital (EGITO; RAFAEL, 2017)?

Considerando Hague e Payton (2010), Forte-Ferreira, Lima e Lima-Neto (2012) e Dudeney, Hockly e Pegrum (2016), aproximamos as atividades ancoradas em tecnologias digitais a 8 tipos de letramentos, a saber: letramento em pesquisa, letramento em informação, letramento em filtragem, letramento intercultural, letramento em hipertexto, letramento impresso online, letramento em rede, letramento pessoal. Além disso, destacamos os gêneros discursivos praticados e as habilidades comunicativas e tecnológicas pressupostas nessas atividades. A seguir, apresentamos os dados resultantes das nossas escolhas teórico-metodológicas.

\section{Resultados e discussão}

Em nossa análise exaustiva do livro didático, identificamos 97 atividades dispostas nos mais variados tópicos das habilidades comunicativas. Dessas, 35 
estabelecem relações com as tecnologias digitais, isto é, aproximadamente $36 \%$ do total da oferta de atividades. Na tabela a seguir (Tab. 1), apresentamos a distribuição dessas atividades nos capítulos que compõem o livro didático.

Tabela 1 - Distribuição das atividades que se ancoram em tecnologias digitais.

\begin{tabular}{|c|c|c|c|c|}
\hline UNIDADE & CAPÍTULO & TOTAL & $\begin{array}{c}\text { TECNOLOGIA } \\
\text { DIGITAL }\end{array}$ & FREQUÊNCIA \\
\hline I & I & 10 & 7 & $70 \%$ \\
\hline $\mathbf{I}$ & II & 10 & 1 & $10 \%$ \\
\hline I & Cultura & 5 & 4 & $80 \%$ \\
\hline $\mathbf{I}$ & Proyecto & 9 & 5 & $55,5 \%$ \\
\hline II & III & 9 & 1 & $11,1 \%$ \\
\hline II & IV & 8 & 6 & $75 \%$ \\
\hline II & Cultura & 1 & 1 & $100 \%$ \\
\hline II & Proyecto & 11 & 2 & $18,1 \%$ \\
\hline III & $\mathrm{V}$ & 10 & 1 & $10 \%$ \\
\hline III & VI & 12 & 3 & $25 \%$ \\
\hline III & Proyecto & 11 & 4 & $36,3 \%$ \\
\hline \multirow[t]{2}{*}{ III } & Culturas & 1 & 0 & $0 \%$ \\
\hline & Total & 97 & 35 & $36 \%$ \\
\hline
\end{tabular}

Fonte: Autoria própria.

Através da Tab. 1, podemos observar que a quantidade do total de atividades é distribuída de forma relativamente equilibrada em função de seus capítulos: o capítulo IV possui o menor número de atividades, isto é, 8 atividades totais; o capítulo VI possui o maior número de atividades, isto é, 12 atividades totais; os capítulos de projeto possuem de 9 a 11 atividades totais; e os capítulos de cultura possuem ou 1 ou 5 atividades totais. No entanto, a distribuição das atividades que se ancoram em tecnologias digitais não é apresentada de forma relativamente estável e equilibrada. Tendo em vista a relação entre a quantidade total de atividades ofertadas nos capítulos e a proporção das atividades ancoradas em tecnologias, destacam-se os capítulos I e IV, com 70 e $75 \%$, respectivamente. A lista de tecnologias pressupostas no livro didático não é extensa, a saber: $\mathrm{CD}$; aparelho de som; celular conectado à internet; computador conectado à internet; câmera fotográfica; e impressora. A seguir, na Fig. 1, uma ilustração de uma atividade que está ancorada em um recurso tecnológico. 
Figura 1: Atividade ancorada em recurso tecnológico.

\section{Reflexión 3: Los lectores y las lecturas de Historias de cronopios y de famas}

1. En un chat de discusiones literarias, algunos lectores del libro opinan sobre los personajes "famas", "cronopios" y "esperanzas".

Con quién(es) te identificas tú cuando sales de viaje: ¿con los famas, los cronopios o las esperanzas? ¿Por qué? ¿Qué características tienes en común con estos personajes? Coméntalo con un(a) compañero(a).

2. Lee lo que dicen algunos lectores de Historias de cronopios y de famas. Luego, crea un nombre de usuario que te identifique y escribe un comentario semejante en este foro virtual:

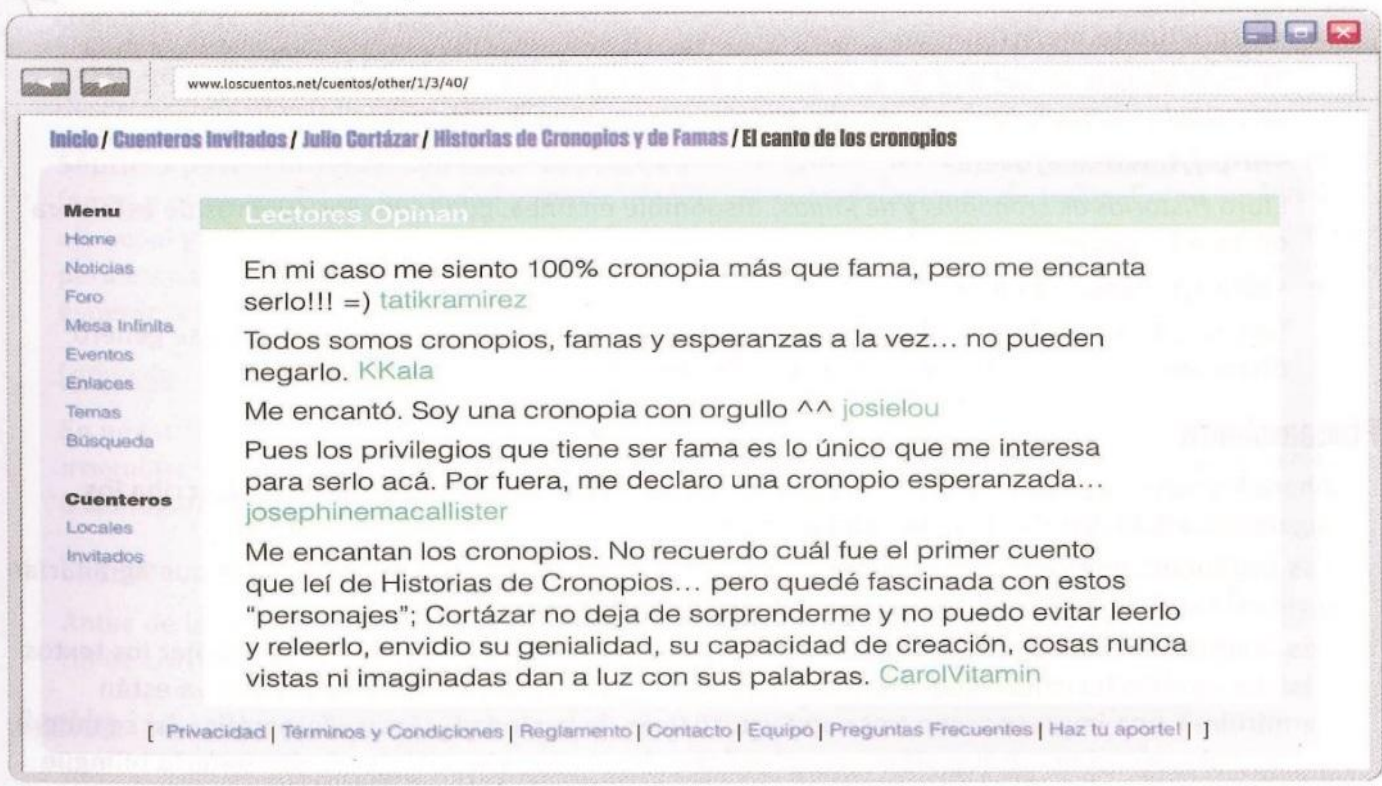

Disponible en: <http://www.loscuentos.net/cuentos/other/1/3/40/>. Acceso el 30 de noviembre de 2015.

Fonte: Coimbra e Chaves (2016, p. 51).

Cabe salientar que o total de 35 atividades que se relacionam com as tecnologias não necessariamente promovem o letramento digital. Algumas atividades, mesmo se relacionando com as tecnologias pressupostas, não promovem nenhum tipo de letramento, tendo em vista a função do recurso meramente ilustrativa. Em outros casos, essa relação entre tecnologias e livro didático se caracteriza por uma função mecanicista, como é o caso da necessidade de uso do CD e equipamento de som para a reprodução de um áudio que segue transcrito nas páginas impressas, isto é, quando a tecnologia é utilizada de forma periférica, sendo dispensável, conforme sinalizam Egito e Rafael (2017).

Das 35 atividades que pressupõem o uso de tecnologias digitais, apenas 13 se relacionam com as tecnologias de forma interativa e significativa, promovendo interações entre os sujeitos ou interações entre sujeito e tecnologia. Nesse caso, a tecnologia se restringe ao celular ou computador conectado à internet. Nessa etapa de análise, percebemos que as atividades para a promoção do letramento digital estão distribuídas, predominantemente, nos capítulos de projeto e de cultura, somando 10 atividades do total de 16 atividades distribuídas em 6 capítulos dessa natureza (ver Tab. 1). Tal constatação nos chama atenção, pois esses capítulos podem ser interpretados como seções extras, seções de apoio ou reforço e, consequentemente, o status de seu 
desenvolvimento pode ser tornar mais optativo ou até mesmo preterido pelo professor em função das escolhas e do tempo destinado às demais atividades presentes nos demais capítulos.

Quanto aos objetivos dessas atividades, eles são bem claros e quase todos sinalizam para a elaboração e/ou interpretação de gêneros discursivos, tais como, cartão postal, fórum virtual, folheto turístico, documentos oficiais em homepage, antologia literária, entre outros. A classificação quanto aos tipos de letramentos relaciona-se diretamente aos objetivos das atividades que pressupõem as tecnologias digitais para sua realização. São eles: investigar, comparar, produzir, pesquisar, acessar, elaborar. A partir da análise das 13 atividades que se relacionam às tecnologias digitais de modo a promover, em tese, o letramento digital, demonstramos, na Tab. 2, a seguir, a frequência dos 8 tipos de letramento digital categorizados no livro didático.

Tabela 2 - Tipos de letramentos digitais identificados.

\begin{tabular}{l|r}
\multicolumn{1}{c|}{ LETRAMENTOS DIGITAIS } & \multicolumn{2}{c}{ FREQUÊNCIA } \\
\hline Letramento em Pesquisa & 11 \\
\hline Letramento em Informação & 10 \\
\hline Letramento em Filtragem & 8 \\
\hline Letramento Intercultural & 7 \\
\hline Letramento em Hipertexto & 6 \\
\hline Letramento Impresso Online & 5 \\
\hline Letramento em Rede & 1 \\
\hline Letramento Pessoal & 1 \\
\hline & Total
\end{tabular}

Fonte: Autoria própria.

Observamos que os letramentos em pesquisa e informação são os mais recorrentes nas e, quase sempre, um está atrelado ao outro, em virtude da proposição da tarefa. Esses tipos de letramentos permeiam quase todo o contexto de atividade escolar, como também são tanto suporte quanto canal para o desenvolvimento de outras atividades que envolvem outros tipos de letramentos. O letramento em filtragem, estratégia usada para reduzir e rastrear a grande quantidade de notícias e informações se repete 8 vezes ao longo das atividades analisadas. O letramento intercultural se relaciona à ampla gama de conexões globais por meio das redes digitais destacando as habilidades para as relações transculturais criativas. Esse letramento foi reconhecido em proposições que envolviam aspectos socioculturais dos povos de países de língua espanhola ressaltados na coleção didática, abordando os tipos e práticas de esportes nesses países, bem como, a literatura, os movimentos sociais e as viagens.

O letramento em hipertexto, capacidade de processar e compreender textos estruturado a partir de hiperlinks, quase sempre, vincula-se aos dois mais recorrente, $\mathrm{o}$ letramento em pesquisa e informação. O letramento impresso online foi identificado em 5 propostas. Esse tipo de letramento está voltado para as produções textuais dos alunos envolvendo as competências de leitura e escrita no contexto das tecnologias digitais: participação dos alunos em fórum virtual por meio de publicação de comentários; produção de folhetos turístico a partir de pesquisa em página web da própria cidade do aluno; elaboração de antologia ilustrada de textos literários; produção de encarte 
contendo repertório de músicas da época da ditadura militar, dentre outras produções textuais.

Por fim, identificamos o letramento em rede e o letramento pessoal, ambos na mesma atividade que se configura na participação dos alunos em um fórum virtual, acompanhamento de postagens e, em seguida, elaboração de nome de usuário e publicação de comentário sobre uma obra trabalhada no projeto de leitura. Desse modo, caracteriza-se como letramento em rede pelo caráter comunicativo e informativo a outrem, através de colaboração e apoio. E quanto ao letramento pessoal pela projeção da identidade online que se deseja.

Em síntese, as relações entre tecnologias digitais e livro didático no ensino de espanhol promovem, em tese, 49 oportunidades de desenvolvimento de 8 tipos de letramento digital em 13 atividades que pressupõem o uso do celular ou do computador conectado à internet. Em todas as atividades, portanto, há a identificação de habilidades funcionais, pois elas precisam ser desenvolvidas por meio de algum equipamento tecnológico. Quanto à criatividade, identificada em propostas que façam com que o aluno produza, adapte ou recrie algo, essa foi percebida através de atividades de elaboração de folheto turístico, produção de contos curtos e posteriormente, sua publicação no blog da escola, edição de texto para dramatização e produção de vídeo poema e áudio poema.

O pensamento crítico e avaliação foi identificado em propostas que necessitavam de um pensamento mais reflexivo por parte do aluno, como o caso das ações de pesquisar, ampliar conhecimento, comparar descrições, ler opiniões e manifestar o pensamento. A atividade que propõe ao aluno a pesquisa sobre músicas que foram censuradas na época da ditadura ilustra esse tipo de categoria. Quanto ao entendimento social e cultural, competência bastante necessária ao estudo de qualquer língua, esse foi identificado em atividades que estão norteadas por temáticas voltadas às manifestações culturais e de identidade dos povos hispanófonos, como a identificação do tipo de turismo (histórico, religioso, rural) que se pratica em cada localidade, exposta por meio de imagens desses locais na ilustração da atividade.

A colaboração encontra-se no pressuposto de participação entre, no mínimo, 2 pessoas para a realização da atividade. A atividade de produzir 2 versões de sarau, tanto para apresentar na escola quanto em modelo em versão virtual, ilustra essa dimensão, uma vez que necessita de mais de um indivíduo para ser desenvolvida. A habilidade de encontrar e selecionar informações justifica-se pela questão dos letramentos mais identificados serem o letramento em pesquisa e informação. Essa dimensão se restringe a procedimentos investigativos, busca de informações relevantes para a pesquisar. Em nossa análise encontramos a atividade de pesquisa sobre os esportes que fizeram parte das Olímpiadas de 2016, por exemplo.

Quanto à comunicação efetiva, caracterizamos as propostas em que haja interação online entre os participantes ou interação entre 2 ou mais pessoas para a elaboração das tarefas determinadas. As ações de ler opiniões em fórum virtual e em seguida, criar um nome de usuário e publicar comentário sobre uma obra literária estudada no projeto de leitura pressupõem e requerem uma comunicação efetiva. Por fim, a segurança eletrônica, relacionada às atividades que apresentam indicações eletrônicas de buscas, apresentam referências confiáveis e de credibilidade para que os alunos façam suas pesquisas e se sintam seguros com as informações. Como ressaltamos anteriormente, essas habilidades foram apresentadas anteriormente por 
Hague e Payton (2010) e puderam ser identificadas nas atividades que tanto pressupõem quanto promovem, em tese, o letramento digital.

Os gêneros propostos nas atividades são diversificados e estão em consonância com os suportes os quais devem ser executados. O tipo de atividade mais recorrentes são as propostas por meio de textos online que constam nas referências assinaladas na atividade para pesquisa mais aprofundada sobre tema abordado na tarefa. Textos informativos para a identificação de conhecimentos pontuais ou gerais sobre determinado assunto, como também, textos publicados em blogs, homepage, campanhas publicitárias na web dentre outros. Este tipo de proposta foi identificado 11 vezes, o que se justifica pelo letramento digital mais encontrado no corpus, letramento em pesquisa e informação.

Sobre as habilidades comunicativas, salientamos que as atividades analisadas reproduzem o modelo previsível em livros didáticos para o contexto de ensino de ELE no nível médio: a prioridade à leitura e à escrita em detrimento da fala e da escuta, não sendo identificada nenhuma atividade de produção oral.

Nossa reflexão sobre os dados nos leva à constatação de que as atividades propostas para o contexto digital ainda se concentram, em sua grande parte, no desenvolvimento de competências comuns ao letramento tradicional impresso. Sobre a predominância das competências de leitura e escrita no corpus analisado, mesmo sendo atividades que poderiam explorar os recursos multimodais como áudio, vídeo, animações, entre outros, como também, fazer uso desses recursos através dos diversos canais de comunicação que a web dispõem, comungamos com a explanação de Rojo (2013b, p. 164), sobre os resultados de estudos que apontam a função estruturadora e cristalizadora de currículos desempenhado pelo livro didático: “[...] embora busquem se adequar a referenciais e propostas curriculares mais recentes, mantêm-se ligados a certa 'tradição' na abordagem de seus objetos de ensino".

Quantos às habilidades tecnológicas, as mais recorrentes são: manuseio da máquina, pesquisa na web e uso de software. Essas habilidades estão em conformidade com os tipos de letramentos digitais identificados. A seguir, passamos às nossas considerações finais sobre nosso trabalho investigativo, destacando implicações pedagógicas e continuidade de pesquisas possíveis.

\section{Considerações finais}

Este trabalho investigativo de análise do livro didático teve como objetivo elucidar as relações entre as tecnologias digitais e o livro didático utilizado nas aulas de ELE do Ensino Médio da escola pública brasileira. Para isso, identificamos as tecnologias digitais pressupostas ou ancoradas nas atividades propostas em livro didático do guia de livros didáticos do Ensino Médio do PNLD do ano de 2018. Além disso, salientamos as potencialidades para a promoção do letramento digital dos alunos, tendo em vista o escopo teórico-metodológico definido para a construção da lupa investigativa utilizada na análise exaustiva.

Os dados analisados evidenciam que as propostas de atividades que fazem relação com as tecnologias digitais e promovem, em tese, tipos de letramentos digitais em variados níveis, podem ser identificadas ao longo do livro 1 da coleção didática 
selecionada. No entanto, há a concentração de atividades em unidades que abordam a cultura hispânica e os projetos que podem ser desenvolvidos pelos alunos.

Em relação às atividades que, em tese, promovem letramentos digitais, essas totalizam 13,4\% de toda a oferta de atividades, isto é, 13 atividades em 97 totais. Essa limitação pode dever-se ao fato de que a vinculação do livro didático a algum aparato tecnológico de forma muito frequente potencializa o risco de apresentação de atividades que requerem tecnologias digitais que podem não acompanhar a realidade do cotidiano de muitos de nossos alunos e escolas brasileiras. Essa realidade é ainda mais potencializada quando tratamos de zonas mais afastadas dos grandes centros, dificultando a concretização das atividades em virtude de questões estruturais e funcionais.

A produção de textos escritos e a compreensão leitora permaneceram no centro das atividades analisadas. Essas atividades podem favorecer o desenvolvimento de outras habilidades comunicativas e há diversidade dos gêneros discursivos apresentados nas propostas, havendo a predominância de gêneros discursos típicos do letramento impresso em situações de ressignificação.

Sobre os tipos de letramentos identificados em nossos dados, avaliamos que estão em consonância com os gêneros discursivos mais recorrentes nas atividades, e que houve uma predominância de letramentos, digamos, comuns ao contexto escolar e correspondentes às tarefas a serem executadas, tais como os letramentos em pesquisa, informação, hipertexto, impresso online, intercultural e filtragem.

Os dados de nossa investigação convidam à reflexão sobre o livro didático e os usos que fazemos dele em sala de aula, cabendo aos professores a seleção das atividades que favoreçam a inserção dos alunos nos contextos de práticas de letramentos. Ponderamos que a promoção do letramento digital é um caminho para alcançarmos muitos dos objetivos educacionais no ensino-aprendizagem de ELE, apresentando-se como uma possibilidade para que o aluno desenvolva o papel de sujeito atuante no processo, podendo portar-se de maneira autônoma, colaborativa, questionadora e, consequentemente, ser sujeito produtor de conhecimento.

Por fim, vale salientar que, apesar da última Reforma do Ensino Médio, por meio da Medida Provisória $\mathrm{n}^{\circ}$ 746, de 2016, não apresentar o ELE obrigatória, a permanência das coleções de Língua espanhola do guia do PNLD 2018 sinaliza para a continuidade do ensino ELE no Ensino Médio, pelo menos, para os próximos anos. O escopo da nossa investigação se limitou à análise do livro didático, enquanto sabemos que ele é apenas um entre os diversos recursos e estratégias muitas vezes atualizados pelo professor de ELE. O desenvolvimento do letramento digital dos alunos pode ser promovido através de outros materiais ou até mesmo de práticas pedagógicas que precisam se tornar objetos de estudo e investigação em possíveis continuidades de pesquisa.

\section{Referências}

COIMBRA, L.; CHAVES, L. S. Cercanía joven: espanhol, $1^{\circ}$ ano: ensino médio. 2. ed. São Paulo: Edições SM, 2016. 
DUDENEY, G.; HOCKLY, N.; PEGRUM, M. Letramentos digitais. Tradução de Marcos Marcionilo. 1. ed. São Paulo: Parábola editorial, 2016.

EGITO, G. A.; RAFAEL, E. L. Utilização de recursos tecnológicos em atividades de produção de texto oral no livro didático de português. Campina Grande: Leia Escola, v. 17, n. 2, 2017. p. 21-31.

FORTE-FERREIRA, E.; LIMA, S. C. LIMA-NETO, V. Propostas de atividades e habilidades comunicativas e tecnológicas no ensino de língua espanhola online no Instituto UFC Virtual. In: CARVALHO, Tatiana Lourenço de (Org.). Espanhol $e$ ensino: relatos de pesquisas. Mossoró: UERN, 2012. p. 119-127.

HAGUE, C.; PAYTON S. Digital literacy across the curriculum - a Futurelab handbook. Bristol: Futurelab, 2010.

LEÓN. E. A. W. Hipertextos digit@les: un desafío en la formación de lectores. Bogotá, 2016. 209f. Dissertação (Maestría En Pedagogía De La Lengua Materna) - Facultad De Ciencias Y Educación, Universidad Distrital Francisco José De Caldas.

ROJO, R. (Org.). Escol@ conectada: os multiletramentos e as TICs. São Paulo: Parábola editorial, 2013a.

ROJO, R. Materiais didáticos no ensino de línguas. In: MOITA LOPES, L. P. (Org.). Linguística aplicada na modernidade recente. São Paulo: Parábola, 2013b.

ROJO, R. Pedagogia dos multiletramentos: diversidade cultural e de linguagens na escola. In: ROJO, R.; MOURA, E. (Org.). Multiletramentos na escola. São Paulo: Parábola Editorial, 2012, p. 11-32.

ZACHARIAS, V. R. C. Letramento digital: desafios e possibilidades para o ensino. In: COSCARELLI, C. V. (Org.). Tecnologias para aprender. São Paulo: Parábola editorial, 2016, p. 15-26.

Recebido em 28 de fevereiro de 2019

Aceito em 30 de maio de 2019 